\title{
Bioterrorismo e a facilidade de acesso à biotecnologia e seus insumos
}

Cesar Koppe Grisolia

\section{Resumo}

Os fundamentalismos surgiram no Ocidente a partir de questões religiosas e posteriormente difundiram-se para outras partes do mundo tomando outras conotações, principalmente políticas. As técnicas de manipulação genética difundiram-se pelas universidades, que formam mestres e doutores com os conhecimentos básicos sobre clonagem gênica, que se tornou de domínio público. Todos os insumos para clonagem gênica podem ser adquiridos por meio de catálogos via internet. Podem-se recrutar profissionais fanáticos e com a competência para a manipulação genética de organismos patogênicos, lado perverso da biotecnologia. Os conflitos étnicos, culturais e religiosos estão associados a um cenário de contrastes entre os países ricos e carentes de matéria-prima e aqueles pobres, mas detentores de insumos básicos e energia, e atingem a sua forma mais aguda nos fundamentalismos. Grupos de fanáticos têm pleno acesso a essa biotecnologia. Estariam assim as populações civis vulneráveis aos ataques do bioterrorismo com armas biológicas geneticamente modificadas?

Palavras-chave: Clonagem molecular. DNA recombinante. Armas biológicas. Guerra biológica. Risco. Bioterrorismo. Engenharia genética.

\section{Resumen}

\section{El bioterrorismo y la facilidad de aceso a la biotecnología y sus insumos}

Los fundamentalismos surgieron en el occidente basado en cuestiones religiosas y posteriormente se difundió para otras partes del mundo, tomando otras connotaciones, sobre todo políticas. Las técnicas de manipulación genética han propagado por las universidades, que forman másteres y doctores con los conocimientos básicos acerca de la clonación génica que se hizo dominio público. Todos los insumos para la clonación génica pueden ser adquiridos a través de catálogos a través de internet. Se pueden reclutar profesionales competentes para la manipulación genética de organismos patogénicos, lado perverso de la biotecnología. Los conflictos étnicos, culturales y religiosos están asociados a un escenario de contrastes entre los países ricos y carentes de materia prima y los países pobres poseedores de insumos básicos y energía, alcanzando su forma más aguda en el fundamentalismo. Grupos de fanáticos tienen total acceso a esa biotecnología. ¿Estarían, de esa forma las poblaciones civiles vulnerables a los ataques del bioterrorismo con armas biológicas genéticamente modificadas?

Palabras-clave: Clonación molecular. ADN recombinante. Armas biológicas. Guerra biológica. Riesgo. Bioterrorismo. Ingeniería genética.

\section{Abstract \\ Bioterrorism and easy access to biotechnology and its inputs}

Fundamentalism arose in the West based in religious matters and afterward diffused to other parts of the world with other connotations, especially political. Genetic manipulation techniques spread to universities, which has given masters and doctors the basic knowledge on gene cloning, which has become public domain. All inputs for gene cloning may be obtained through online catalogs. Fanatic professionals may be recruited, with qualification for genetic manipulation of pathogenic organisms, the negative side of biotechnology. Ethnic, cultural and religious conflicts are linked to a series of contrasts between countries that are rich but with a lack of raw materials and the poor countries that possess basic input and energy sources, when it reaches the highest fundamentalist form. Fanatic groups have complete access to this biotechnology. Are civilian populations in vulnerable to bioterrorist attacks involving genetically modified biological weapons?

Key words: Cloning, molecular. DNA, recombinant. Biological warfare agents. Biological warfare. Risk. Bioterrorism. Genetic engineering.

Pós-doutor grisolia@unb.br - Universidade de Brasília, Brasília/DF, Brasil.

\section{Correspondência}

Universidade de Brasília - UnB, Laboratório de Genética Toxicológica, GEM/IB, Bloco F, Térreo CEP 70910-900. Brasília/DF, Brasil.

Declara não haver conflito de interesse. 
Os fundamentalismos, para efeito do presente estudo, são provenientes das correntes mais conservadoras do protestantismo que se desenvolveu nos Estados Unidos da América (EUA) entre 1870 e 1925. Os fundamentalistas protestantes eram radicalmente opostos à modernização do cristianismo. A Revolução Iraniana e o surgimento da Al-Qaeda demonstraram que o fundamentalismo tem caráter transnacional e transcultural, tornando-se um fenômeno global ${ }^{1}$.

O termo fundamentalismo surgiu com os jornalistas no início da década de 70 , ao se referirem aos protestantes cristãos e aos radicais muçulmanos que defendem o conservadorismo social mediante mobilização e radicalização do tradicionalismo político e cultural e inflexibilidade religiosa ${ }^{2}$. A modernização da sociedade com a urbanização faz surgir o pluralismo cultural e religioso, que pode ser visto como erosão da identidade religiosa e capaz de criar ameaças às instituições e comportamentos seculares. De acordo com Riesebrodt ${ }^{3}$, ainda não existem respostas para se entender como esses movimentos surgem, por que estão surgindo e qual o seu significado para o futuro da sociedade. É nas religiões fundamentalistas que surgem os grupos extremistas, responsáveis pela violência e por conflitos incitados para marcar posição e presença.

Segundo Leonardo Boff ${ }^{4}$, o fundamentalismo não está associado apenas ao fanatismo religioso. Todos os sistemas - quer culturais, científicos, políticos, econômicos e artísticos - que se apresentam como detentores exclusivos de uma verdade e portadores de solução única para os problemas devem ser considerados fundamentalistas. Vivemos atualmente sob o império feroz de vários fundamentalismos. O fundamentalismo é entendido como a radicalização da verdade, em que cada grupo se autointitula detentor exclusivo dessa verdade e apoia-se em um estado de poder econômico e/ou político para impô-la aos demais. As religiões ensinam aos seus adeptos que eles são os eleitos e os que não são do grupo, são contra eles. Nada há de surpreendente nisso, dada a origem da maioria das religiões em cultos oriundos de sociedades tribais divididas e violentas ${ }^{5}$.

A natureza social dos seres humanos pode ser atribuída aos primórdios da vida humana pelos indícios fósseis dos caçadores-coletores das savanas africanas. Somente ao se associarem em grupos nossos ancestrais puderam abater a grande caça e se alimentar de carne. Com isso enriqueceram suas dietas, passo fundamental ao progresso evolutivo da espécie. Quando nos associamos em grupos au- mentamos a possibilidade de atingir objetivos individuais com sucesso.

Desde essa era primordial já havia a divisão do trabalho, de acordo com as habilidades individuais. As principais conquistas da humanidade foram feitas mediante a coalizão de indivíduos com habilidades específicas. Como, por exemplo, coalizões entre indivíduos fisicamente mais fracos, mas com inteligência para construir utensílios, com aqueles indivíduos de grande força física, mas sem tais habilidades. Juntos, um supria a deficiência do outro e ambos tinham sucesso na luta pela sobrevivência. Assim, por mais moderna e tecnológica que seja a nossa sociedade do segundo milênio, a tribalização permanece enraizada em nossos instintos ${ }^{5}$. Em vista disso, perduram os nacionalismos, as fronteiras, grupos internos e grupos externos e, consequentemente, os conflitos. Tudo isso seria a consequência de nossa herança genética-evolutiva de símios que vivem em bandos e formam coalizões. A ameaça do inimigo externo contribui para aumentar a coesão do grupo, pois há segurança na quantidade ${ }^{5}$.

\section{O pano de fundo para o bioterrorismo}

A expansão da humanidade foi tal que hoje vivemos em uma cidade global e as fronteiras e os nacionalismos ganham outra conotação. A expansão geográfica e crescimento demográfico aumentaram drasticamente a demanda por bens de consumo a qual, por sua vez, incidiu sobre a demanda de energia. Em consequência, cresceram as demandas por alimentos e por mais terras. É assim, nesse cenário, que a biotecnologia genômica está inserida, trazendo a perspectiva do aumento da produção de alimentos e energia para a humanidade e a perspectiva de novas terapias mais eficientes para doenças como o câncer e neurológicas, entre outras.

A biotecnologia genômica nasceu no Ocidente, de modo acadêmico, sendo logo em seguida aproveitada pela indústria biotecnológica. O marco desse processo foi a criação da empresa Genentech, em 1976, nos EUA. Hoje, o mercado conta com mais de 2.500 produtos biotecnologicamente desenvolvidos, devidamente protegidos por patentes, os quais estão presentes no dia a dia de maneira mais ou menos conhecida pela população.

A possibilidade de aumentar drasticamente a produção de alimentos, de promover curas inéditas e, principalmente, de se obter no mercado lucro exorbitante com os produtos desenvolvidos incentivou a biotecnologia genômica. Em decorrência, esse 
conhecimento se difundiu para todas as universidades e instituições de pesquisas. Qualquer aluno com um mestrado ou doutorado em biologia ou genética molecular sabe identificar e isolar um gene, cloná-lo e multiplicá-lo.

Se a difusão do conhecimento atende ao objetivo de franquear a toda a humanidade o acesso a novas tecnologias potencialmente benignas, não se pode esquecer que atualmente qualquer egresso da pós-graduação nessas áreas pode ser recrutado por um grupo fundamentalista para executar essas técnicas com objetivos espúrios. Genes que codificam toxinas podem ser sintetizados em laboratório e, então, inseridos em plasmídeos bacterianos. Além disso, pode-se inserir também nessa bactéria outros genes de resistência a antibióticos e levar ao fermentador para se produzir grandes quantidades. Como produto final desse processo, tem-se um organismo patogênico altamente resistente que pode ser transportado facilmente para qualquer lugar dentro de pequeno frasco.

Os insumos para se fazer a clonagem de um gene estão disponíveis na internet e podem ser comprados por catálogo. Tais insumos vão desde equipamentos, como máquina para sintetizar cópias de genes e máquina para amplificar segmentos de DNA (termocilcador), equipamentos de eletroforese, equipamentos de microinjeção de DNA e outros, bem como todos os reagentes necessários para executar a clonagem, como as enzimas de restrição, sequências iniciadoras de síntese de DNA (primers), conforme definidos na metodologia deste artigo. A facilidade de acesso a esses insumos torna o bioterrorismo uma possibilidade quase palpável.

Pensando-se pela perspectiva de grupos fundamentalistas, as vantagens na adoção desse método bélico são várias. A detecção das instalações para a produção de armas biológicas por meio de satélites é difícil, uma vez que não exigem grande aparato. Além disso, talvez a razão mais importante, os artefatos podem ser facilmente transportados e disseminados, podem ser transmitidos pessoa a pessoa, causam alta mortalidade, provocam pânico nas populações, levam a rupturas sociais, são difíceis para se tomar ações preventivas e podem desestabilizar governos, tornando-os mais atrativos aos grupos fanáticos terroristas. Pode-se construir um instrumento biológico de destruição em massa muito mais barato que uma bomba atômica e igualmente eficiente.

Atualmente, grandes empresas multinacionais patenteiam genes e processos de clonagens relacionados à produção de alimentos e medicamentos - insumos essenciais da humanidade. Tais processos têm a salvaguarda de instituições internacionais que estão acima do poder dos Estados e das necessidades e carências das populações. As nações industrializadas são as maiores detentoras dessas patentes, pois justamente abrigam as sedes dessas empresas, o que reforça a manutenção do estado da arte.

Entretanto, mesmo esse aparente controle não é capaz de impedir que grupos marginais a esse processo tenham acesso a essa biotecnologia e venham a executar processos de clonagem. O código genético é universal, isto é, o mesmo para a grande maioria dos seres, e as tecnologias de transferência de genes são de domínio público. Com isso, os genes a serem clonados e amplificados, e os objetivos do uso dessa tecnologia, podem ser os mais variados possíveis, incluindo-se aqueles apregoados pelos grupos fundamentalistas. A produção de vírus patogênicos como arma biológica é bem mais complexa e cara que as bactérias patogênicas, que são de fácil obtenção e multiplicação pois no meio ambiente os vírus são mais instáveis e de mais difícil disseminação.

Assim, esse estudo tem por objetivo contextualizar a biotecnologia genômica no cenário da construção de armas biológicas. Buscou-se verificar o que seria necessário para produzir armas biológicas e qual o grau de dificuldade deste processo, tendo em vista que a obtenção e o domínio do conhecimento sobre a manipulação genética de microrganismos patogênicos fugiu ao controle do Estado. Considera-se tal levantamento importante para que a academia, as instituições internacionais e os governos possam pensar acerca desta possibilidade, que a cada dia parece mais próxima à esfera das probabilidades. Ao mesmo tempo em que se disseminam os fundamentalismos tanto no Oriente como no Ocidente, as sociedades tornam-se vulneráveis a esse tipo de risco biológico. O maior exemplo disso foram os episódios de contaminação por Antrax, nos EUA, após o ataque às Torres Gêmeas - fato também atribuído à rede terrorista Al-Qaeda.

\section{Método}

O método para levantar os dados que subsidiaram estas reflexões consistiu em dois procedimentos básicos: 1) pesquisar na literatura todos os insumos necessários para a construção de bactérias recombinantes, como reagentes e equipamentos; 2 ) pesquisar na internet as empresas que comercializam esses insumos e equipamentos e a disponibi- 
lidade de entrega imediata a qualquer endereço, mesmo que a compra seja feita por pessoa física.

A pesquisa na literatura utilizou as seguintes fontes: 1) o levantamento na internet foi feito a partir das palavras-chave clonagem gênica, manipulação genética, engenharia genética, DNA recombinante, genética molecular, biologia molecular, organismos geneticamente modificados, enzimas de restrição; 2) os sites foram pesquisados a partir do site de busca mais conhecido: o Google. O processo de pesquisa foi empreendido durante seis meses (julho a dezembro de 2011), sendo que os achados foram catalogados extensivamente e, a seguir, utilizados como substrato às considerações do autor.

\section{Resultados}

\section{Equipamentos}

Biofermentador: tem a capacidade para a produção de bactérias em grande escala. Fácil de adquirir e de operar. Equipamentos para um laboratório de microbiologia ou biologia molecular: estufas, câmaras acéticas, microscópios, centrífugas, banho-maria, termociclador, cubas de eletroforese, fonte de eletroforese, microinjetor de DNA;

Reagentes: meio de cultura bacteriana, kits de anticorpos, DNA, enzimas de restrição, sais para a preparação de solução-tampão para correr as eletroforeses, corantes para os géis de eletroforese, reagentes para purificação e eluição de DNA. Insumos para a reação de amplificação de segmentos de DNA, chamada de PCR (Polymerase Chain Reaction), que demanda enzima taq polimerase, adenina, citosina, guanina e timina-dinucleotídio-trifosfatos, primers específicos (iniciadores da reação), kits para eluição do DNA das bandas do gel de eletroforese e kits de purificação do DNA;

Criação do DNA recombinante: (insumos) enzimas de restrição, que cortam o DNA nas sequências que programarmos, enzimas DNA ligase, DNA polimerase, polinucleotídeo quinase. Seleção dos melhores plasmídeos para servirem de vetor do gene para dentro da bactéria;

Transformação celular: a eletroporação é uma técnica usada para tornar a célula competente, isto é, para facilitar a entrada dos plasmídeos que estão do lado de fora, fazendo-os penetrar na célula bacteriana e serem incorporados no genoma da bactéria. Outra técnica é a microinjeção de DNA, mais empregada para a transformação genética de células eucariotas.

\section{Fornecedores de insumos e equipamentos}

Todos os insumos citados foram pesquisados nas páginas da internet, mediante busca por empresas fornecedoras desses reagentes e equipamentos de laboratório. Tanto no Brasil como em outros países, estão sempre disponíveis para remessa por meio de empresas de entrega de encomendas expressas. Assim, sua aquisição é um processo impessoal, pois não há qualquer contato entre o fornecedor e o grupo que vai executar a clonagem gênica. $O$ primeiro contato com as empresas que vendem esses equipamentos e insumos é mediante uma solicitação de cotação. Qualquer que seja o país, os valores desses materiais estão ancorados no dólar americano. Os insumos podem variar entre 900 dólares por um kit de reação de PCR, 10.000 dólares em termociclador, até 40.000 dólares em um equipamento de microinjeção de DNA. Considerando todos os insumos e equipamentos, com 350.000 dólares pode-se montar um laboratório com os itens básicos para se fazer clonagens gênicas. Além disso, pode-se obter gratuitamente manuais de clonagem gênica na internet. Saliente-se, ademais, que os preços dos equipamentos e reagentes são perfeitamente acessíveis aos grupos terroristas/fundamentalistas.

Pesquisa e controle sobre as condições de disponibilidade dos genes que produzem as toxinas mais deletérias ao homem

Os genes e agentes biológicos mais conhecidos, com potencial de uso no bioterrorismo, estão sob a fiscalização e controle do Center for Disease Control (CDC-USA), que possui um banco de informações sobre as principais bactérias e toxinas que podem ser usadas no bioterrorismo, bem como os antídotos e procedimentos a serem adotados em caso de ataque, haja vista que os EUA são um dos principais alvos desse tipo de ação.

Genes e agentes candidatos a clonagem para bioterrorismo ${ }^{6}$

Vírus: encefalite equina, ebola, febre amarela, morbillivirus equina, varíola, febre hemorrágica;

Bactérias: Bacillus anthracis, Brucella, Clostidium botulinium, Franciella tularensis;

Toxinas: aflatoxina, toxina botulínica, toxina clostridium, ricina, saxitoxina, Staphylococo enterotóxico, tetrodoxina, micotoxina T-2. 


\section{Discussão sobre as origens dos riscos}

Em uma era pautada por conflitos étnicos e religiosos, de disputas por reservas de mercados e por hegemonia ideológica, os grupos fundamentalistas podem fazer uso da biotecnologia genômica como um instrumento a favor de sua causa. Partindo-se do princípio de que qualquer gene pode ser clonado em qualquer organismo, e que todos os insumos para a realização desse processo estão amplamente disponíveis, a construção de organismos geneticamente modificados, para serem usados como instrumentos (armas) dessa ou daquela causa (fundamentalismo), deixa de ser ficção para se tornar uma probabilidade real de ocorrência.

Assim, a "construção" de bactérias altamente patogênicas, de fungos infecciosos e de novas pragas agrícolas por facções fundamentalistas pode colocar em risco toda a humanidade, vez que somos uma população planetária, com um fluxo de pessoas e produtos bastante dinâmico. Todos os conflitos atuais decorrem de questões econômicas, religiosas e étnicas, bem como das disputas pela hegemonia sobre recursos essenciais para a humanidade. Nesse contexto, a biotecnologia genômica surge como mais um instrumento que os grupos fundamentalistas podem lançar mão.

As consequências da disseminação de organismos patogênicos geneticamente modificados são imprevisíveis, pois os micróbios não conhecem culturas, línguas, territórios e/ou fronteiras geopolíticas. Devido a facilidade de transporte e o fluxo de pessoas, qualquer que seja o local de origem da contaminação o impacto torna-se internacional. Considere-se nesse quadro que a velocidade de transmissão de patologias infecciosas cresceu de maneira inolvidável no século $X X$ em decorrência do aprimoramento dos meios de transporte, aéreo e terrestre, que propiciam a disseminação pandêmica de enfermidades. Acrescente-se, ainda, a popularização do uso destes meios, que torna o controle epidêmico muito mais difícil e, algumas vezes, demorado.

Assim, considerando todos estes fatores, é imprescindível questionar: qual é - de fato - a nossa vulnerabilidade frente aos grupos fanáticos que adquirem o domínio da tecnologia de manipulações genéticas? Pelo exposto, pode-se dizer que passamos a conviver com esse risco, pois o que se pode perceber neste estudo é que os insumos e equipamentos para a produção de armas biológicas são de fácil aquisição e o conhecimento para sua produção, largamente disseminado. $O$ bioterrorismo não será utilizado em campos de batalha em época de guerra, como aconteceu com as armas químicas (gases de guerra) na Segunda Guerra Mundial, mas sim para aterrorizar populações civis e subjugar gover$\operatorname{nos}^{7}$. Entretanto, os métodos de disseminação conhecidos são bastante restritos, com relativo sucesso em ambientes fechados, para contaminar alimentos, para atacar corporações que são ícones em seus países ou destruir plantações. As disseminações mais amplas de microrganismos patogênicos geneticamente modificados requerem pulverizações em forma de aerossol, que demandam o uso de equipamentos mais sofisticados, constituindo, assim, uma barreira para os grupos terroristas ${ }^{8}$.

Aqueles que se utilizam da bioviolência para ataques são mais organizados e mais focados em seus propósitos do que as instituições dos países responsáveis por salvaguardar seus cidadãos. Pois as estratégias para prevenir a bioviolência requerem ações internacionais que demandam muitos esforços diplomáticos, e a maioria dos países não tem essas articulações. A subestimativa do real perigo da bioviolência leva os países a adotarem medidas erradas tanto de prevenção como de contingência ${ }^{8}$. Paralelamente, as técnicas de sequenciamento genômico de bactérias e vírus tornaram-se mais rápidas e eficientes. Assim, os genomas de todos os microrganismos patogênicos que podem atingir o homem, animais domesticados e plantações agrícolas já foram sequenciados. A técnica de PCR é bastante rápida e sensível, constituindo-se em eficiente método de investigação forense para rastrear tais organismos. Resultados de análise genética de microrganismos com essa técnica, podem dar respostas em menos de $24 \mathrm{~h}^{9}$. No mundo, os EUA são o país melhor estruturado para o antibioterrorismo. Por meio do banco das "assinaturas genéticas" dos patógenos no $\mathrm{CDC}$, tem-se condições de diagnótico quase que imediato ${ }^{6}$.

É importante sublinhar, ainda, que a disseminação de um agente biológico em dada população ocorre, inicialmente, de modo silencioso e gradativo. Somente após o registro de vários casos, com os mesmos sintomas da infecção, é que as autoridades públicas responsáveis acionarão as devidas providências. Considere-se, ademais, que em muitos casos, a depender da política de Estado, os organismos internacionais tardarão a ser acionados dado o temor do governo de muitos países da ingerência internacional pelos órgãos de controle internacio- 
nal, como a Organização Mundial da Saúde (OMS), ou pelas potências hegemônicas. Assim, o controle e a busca por solução tenderão a ser retardados, aumentando ainda mais a vulnerabilidade dos seres humanos em todo o planeta.

\section{Considerações finais}

As informações levantadas neste estudo relativas à facilidade de aquisição de insumos e equipamentos, à ausência de controle deste processo, bem como à disseminação do conhecimento sobre a técnica de produção, permitem inferir que há razões para considerar que o risco de bioterrorismo seja iminente e preocupante. As relações das nações industrializadas com os demais países e culturas estabelecem um estado de vulnerabilidade, em que tais países são explorados e suas populações e culturas subjugadas. São vulneráveis aqueles que são explorados em suas riquezas, oprimidos em sua cultura e têm negados os seus direitos à cidadania.

O bioterrorismo poderia ser, então, o instrumento pelo qual essas populações ou grupos vulneráveis poderiam responder à opressão. Dado o crescente hiato econômico e de poder entre indivíduos, grupos e populações em todo o planeta, maximizado pela globalização, não é infundado imaginar que tal situação possa ocorrer. E diante desta iminência é indispensável estimular a reflexão ética.

\section{Referências}

1. Emeerson OM, Hartman D. The rise of religious fundamentalism. Annu Rev Sociol. 2006;32:12744.

2. Schneider S. Fundamentalism and paranoia in groups and society. Group. 2002;26(1):17-27.

3. Riesebrodt M. Fundamentalism and the resurgence of religion. Numen. 2000;47(3):266-87.

4. Boff L. Fundamentalismo: a globalização e o futuro da humanidade. Rio de Janeiro: Sextante; 2002

5. Ridley M. As origens da virtude. Rio de Janeiro: Record; 2000.

6. Slezak T, Kuczmarski T, Ott L, Clinton t, Medeiros D, Smith J et al. Comparative genomics tools applied to bioterrorism defense. Briefing in Bioinformatics. 2003;4(2):133-49.

7. Simms M. On linking business ethics, bioethics and bioterrorism. J Bus Ethics. 2004;51:211-20.

8. Kellman B. Bioviolence, preventing biological terror and crime. Chicago: Cambridge Press; 2007.

9. Crighton T, Hoile R, Coleman V. Comparison of quantitative PCR and culture-based methods for evaluating dispersal of Bacillus thuringiensis endospores at a bioterrorism hoax crime scene. Forensic Science International. 2012;219:88-95.

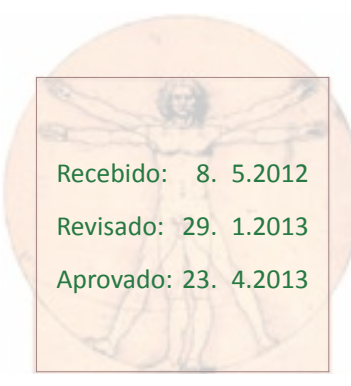

